\title{
Modeling of ultimate load for R.C. beams strengthened with Carbon FRP using artificial neural networks
}

\author{
Dr. Salim T.Yousif \\ College of Engineer University of Mosul \\ Majid A. AL- Jurmaa \\ Iraq
}

\begin{abstract}
The use of carbon fiber reinforced composite materials is an accepted technology that is being used in practice to strengthen existing reinforced concrete $(\mathrm{R} / \mathrm{C})$ elements. An artificial neural network (ANN) model was developed using past experimental data on flexural failure of R/C beams strengthened by carbon FRP. The input parameters cover the carbon sheet properties, beam geometrical properties and reinforcement properties; the corresponding output is the ultimate load capacity. The ANN prediction and the measured experimental values are compared with load prediction of ACI440.2R-02 formulas. A sensitivity study of parameters that affect ultimate load of R/C beams strengthened by carbon FRP is carried out. It is concluded that ANN can predict, to a good degree of accuracy, the ultimate load capacity of R/C beams strengthened by carbon FRP and it is a viable tool to carry out parametric study of flexural behavior of R/C beams strengthened by carbon FRP.
\end{abstract}

Keywords: carbon FRP, Reinforced Concrete Beam, Ultimate Load, and Neural Network.

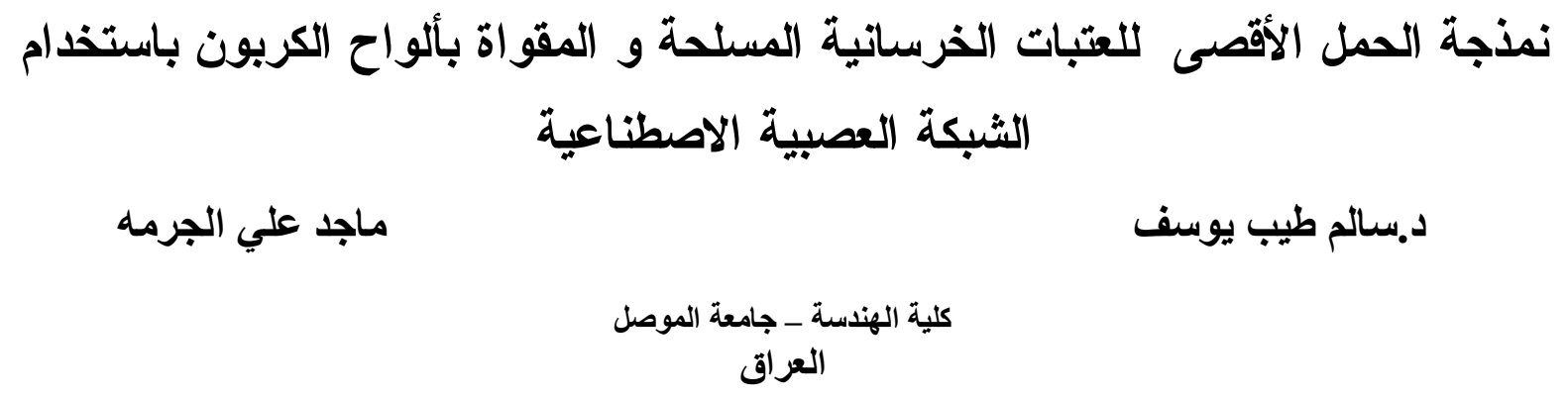

تستخدام الواح الكاربون عمليا كثقنية جيدة لتقوية الاعتاب الخرسانية المسلحة ، تم تطوير نموذج شبكة عصبية

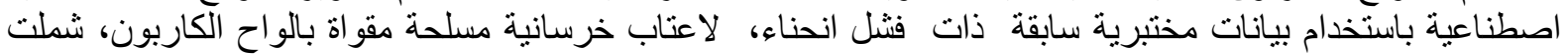

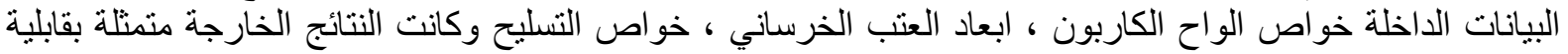

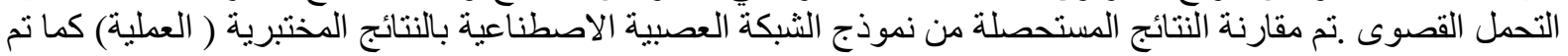

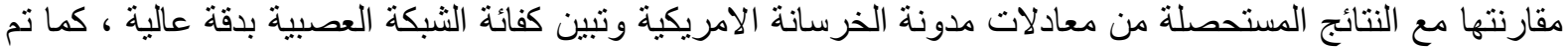

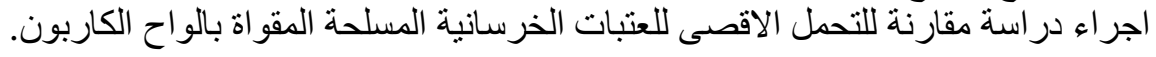




\section{Introduction}

Carbon fiber is a tension load element that can be used to strengthen concrete structures against flexure, shear, or compression, depending on how the carbon fiber strips are oriented and where they are placed. It is a proven method of providing structural strengthening that is lighter, non corrosive, and less labor intensive than the application of steel plates or exterior post-tensioning. It is also an effective technique to rehabilitate and expend the life expectancy of a deteriorated structure when the cost of replacing it. Repairing structures with carbon fiber is usually motivated by requirements for earthquake strengthening, higher service loads, or simply to substitute for deteriorated steel reinforcement. The use of carbon fiber reinforced composite materials is an accepted technology that is being used in practice to strengthen existing reinforced concrete elements. A significant number of studies, experimental and analytical, have been conducted on flexural strengthening of reinforced concrete beams using composites. The tests have indicated that the strengthened specimens fail predominantly by debonding of the composites from the surface of the concrete before reaching the rupture strength of the laminates. [1]

CFRP composites, used in the repair of beams and slabs as external tensile reinforcement, increase the strength (ultimate limit state) and the stiffness (serviceability limit state) of the structure, smaller deflections, or simply to substitute for deteriorated steel reinforcement. Unfortunately, the increase in strength and stiffness is sometimes realized at the expense of a loss in ductility, or capacity of the structure to deflect in elastically while holding a load close to its capacity. In recent years several researchers used ANN to predict structural behavior of reinforced concrete.

Neural networks are an information processing techniques based on the way biological nervous systems, such as the brain, process information. The fundamental concept of neural networks is the structure of the information processing system [2]. Composed of a large number of highly interconnected processing elements or neurons, a neural network system uses the human-like technique of learning by example to solve problems. The neural network is configured for a specific application, such as data classification or pattern recognition, through a learning process called training. Just as in biological systems, learning involves adjustments to the synaptic connections that exist between the neurons. Neural networks can differ on the way their neurons are connected; the specific kinds of computations their neurons do; the way they transmit patterns of activity throughout the network; and the way they learn including their learning fate. Neural networks are being applied to an increasing large number of real world problems. Their primary advantage is that they can solve problems that are too complex for conventional technologies; problems that do not have an algorithmic solution or for which an algorithmic solution is too complex to be defined. The multi-layer perceptron is the most widely used type of neural network. It is both simple and based on solid mathematical grounds. Input quantities are processed through successive layers of "neurons". There is always an input layer, with a number of neurons equal to the number of variables of the problem, and an output layer, where the perceptron response is made available, with a number of neurons equal to the desired number of quantities computed from the inputs. The layers in between are called "hidden" layers. Each neuron of a layer other than the input layer computes first a linear combination of the outputs of the neurons of the previous layer, plus a bias. The coefficients of the linear combinations plus the biases are called the weights. Neurons in the hidden layer then compute a non-linear function of their input. Generally, the non-linear function is the sigmoid function. Once the networks are considered to be trained, testing data are presented to it and outputs are compared with the experimental or observed results. In this study, a multi-layer feed-forward neural network is 
used. In a multi-layer feed-forward neural network, the artificial neurons are arranged in layers, and all the neurons in each layer have connections to all the neurons in the next layer. Associated with each connection between these artificial neurons, a weight value is defined to represent the connection weight. Fig.(1) shows architecture of a multi-layer feed-forward neural network with an input layer, an output layer, and one hidden layer. The operation of the network consists of a forward pass through the network. A number of learning rules are available. The back propagation learning algorithm is used in this study.

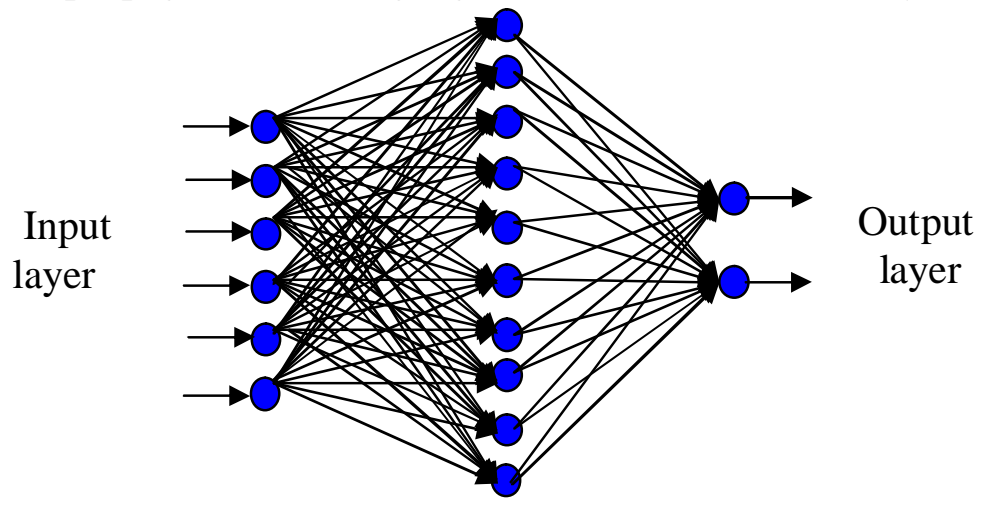

Hidden layer

\section{Fig.(1) Architecture of multilayer feedforward neural network with one hidden}

Hegazy et-al. [3] analyzed the Neural Network Approach for Predicting the Structural Behavior of Concrete Slabs. Neural networks have been used as a means to develop efficient predictive models of the structural behavior of concrete slabs. Four neural networks have been developed to model the load deflection behavior of concrete slabs, the four neural networks were trained and tested using the experimental results of 38 full-scale slabs.

Haj-Ali et-al [4] presented a new approach to generate nonlinear and multi-axial constitutive models for fiber reinforced polymeric (FRP) composites using artificial neural networks (ANNs). The new nonlinear ANN constitutive models are complete and have been integrated with displacement-based FE software for the nonlinear analysis of composite structures. The proposed ANN constitutive models are trained with experimental data obtained from off-axis tension/compression and pure shear (Arcan) tests. The proposed ANN constitutive model is generated for plane-stress states with assumed functional response in some parts of the multiaxial stress space with no experimental data. The ability of the trained ANN models to predict material response is examined directly and through $\mathrm{FE}$ analysis of a notched composite plate.

B. B. Adhikary and H. Mutsuyoshi [5] presents the development of artificial neural network models for predicting the ultimate shear strength of steel fiber reinforced concrete (SFRC) beams. Two models are constructed using the experimental data from the literature and the results are compared with each other and with the formula proposed by Swamy et al. and Khuntia et al. It is found that the neural network model, with five input parameters, predicts the shear strength of beams more closely than the network with four input parameters. Moreover, the neural network models predict the shear strength of SFRC beams more accurately than the above-mentioned formulas.

In this study an ANN with back-propagation is used to predict the ultimate load capacity of RC beams strengthened with Carbon FRP. Seventeen parameters are used as input for the ANN at first stage. Several network architectures with different number of hidden layers and different number of neurons in the hidden layers were tried to reach a reasonable architecture. 
A parametric study for behavior of RC beams strengthened with Carbon FRP is carried out through the study.

\section{Ultimate Flexural Strength of R.C. Beams Strengthened by CFRP}

There are several modes of failures in concrete structural elements. Flexural failure is one of the most serious and undesirable modes of failure due its severity and brittleness. R/C members resist bending moment using several mechanisms. Experimental investigations to predict the flexural strength of $\mathrm{R} / \mathrm{C}$ members have been carried out by several researchers and several empirical formulas[7-23], based on experimental results, have been developed, Some of these formulas are used in prominent design codes such as the American Concrete Institute (ACI 440 R2) [6]. These formulas are used to predict the bending moment of concrete beams strengthen by CFRP, carry two point load as shown in figure (2) and they are functions of several flexural parameters.

Accurate prediction of the ultimate flexural strength of reinforced concrete beams strengthening by Carbon FRP is of prime importance for developing a reliable method for their design. For this purpose, many experiments have been carried out to investigate the behavior of such beams. The data collected from these experiments constitute the basis of some of the expressions available in the literature for analytically predicting the ultimate strength of these beams.

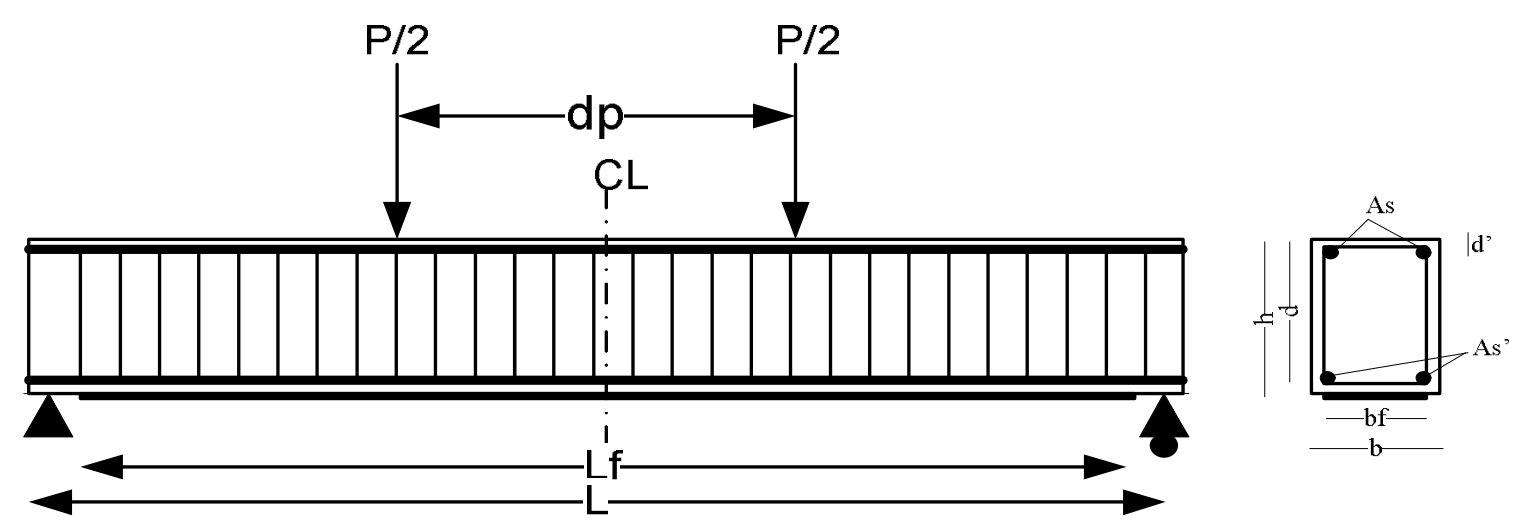

Fig. (2) Rectangular reinforced concrete beam.

\subsection{ACI 440.2R-02 [6]}

In order to prevent debonding of the FRP laminate, a limitation should be placed on the strain level developed in the laminate. ACI 440.2R-02 [6] applies limit values for the ultimate strain of FRP sheet given by the following equations:

$$
\begin{aligned}
& k m=\frac{1}{60 \epsilon_{f u}}\left(1-\frac{n E_{f} t_{f}}{360000}\right) \leq 0.9, \quad n E_{f} t_{f} \leq 180000 \\
& k m=\frac{1}{60 \epsilon_{f u}}\left(\frac{90000}{n E_{f} t_{f}}\right) \quad \leq 0.9, \quad n E_{f} t_{f}>180000
\end{aligned}
$$




$$
\begin{aligned}
& \varepsilon_{f u}=C_{E} \varepsilon_{f r p} \\
& \varepsilon_{f e}=k m \varepsilon_{f u}
\end{aligned}
$$

$C_{E}, \varepsilon_{f u}, E_{f}, t_{f}, \varepsilon_{f e}$, and $n$, are the environmental reduction factor for various FRP materials, ultimate strain, modulus of elasticity, thickness, effective strain and number of layers of CFRP sheet the nominal bending moment at failure is given by :

$M_{n}=A_{s} \sigma s\left(d-\frac{\gamma c}{2}\right)+\psi f r p A_{f} E_{f} \varepsilon_{f e}\left(d-\frac{\gamma c}{2}\right)+A_{s}^{\prime} \sigma_{s}^{\prime}\left(\frac{\gamma c}{2}-d^{\prime}\right)$

Where $\psi$ frp the reduction factor for CFRP sheet.

The ultimate bending moment is calculated by the following equation:

$M_{u}=\varphi M_{n}$

Based on ACI440, to provide ductility, the design bending moment is calculated provided that the tension steel strain be greater than 0.005 . Therefore, a strength- reduction factor should be used as below:

$\varphi=\left\{\begin{array}{c}0.9 \\ 0.7+\frac{0.2\left(\epsilon_{s}-\epsilon_{y}\right)}{0.005-\epsilon_{y}} \\ 0.7\end{array}\right.$

$$
\left.\begin{array}{c}
\epsilon_{s} \geq 0.005 \\
\epsilon_{y}<\epsilon_{s}<0.005 \\
\epsilon_{s} \leq \epsilon_{y}
\end{array}\right\}
$$

\section{Artificial Neural Network Models and Training}

\subsection{Experimental Data:}

From the experimental data collected from the literature cover the flexural strength of the specimens, the ultimate load capacity are calculated, which are simply supported and subjected to two point loads acting symmetrically with respect to the centerline of the span see figure (2). This case provides a larger amount of data than other cases do, which is essential for better training of a network. During the collection of the data, specimens that do not have flexural failures have been excluded from the training set. The basic parameters that control the ultimate load of beams, based on previous research works are listed in table (1)

The experimental data include 85 beam results, which are taken from the tests carried out by references [7-23], the data are rearranged in such a way that 17 basic parameters are listed as input values and the ultimate load is included as the corresponding output value. The data collected contain the ranges as in table 1 . 


\section{Table (1) Range Data of Input Parameters}

\begin{tabular}{|l|c|c|c|c|}
\hline Parameter & Sample & Minimum & Maximum & Unit \\
\hline Length of beam & $\mathrm{L}$ & 914 & 5280 & $\mathrm{~mm}$ \\
\hline Width of beam & $\mathrm{bw}$ & 100 & 368 & $\mathrm{~mm}$ \\
\hline Height of beam & $\mathrm{h}$ & 102 & 467.2 & $\mathrm{~mm}$ \\
\hline Effective span of beam & $\mathrm{cl}$ & 812 & 4800 & $\mathrm{~mm}$ \\
\hline Distance between point loads & $\mathrm{pl}$ & 152 & 1600 & $\mathrm{~mm}$ \\
\hline Length of carbon sheet & Lf & 450 & 5000 & $\mathrm{~mm}$ \\
\hline Width of carbon sheet & $\mathrm{Bf}$ & 50 & 368 & $\mathrm{~mm}$ \\
\hline Thickness of carbon sheet & $\mathrm{tf}$ & 0.11 & 2.8 & $\mathrm{~mm}$ \\
\hline Area of tension reinforcement & $\mathrm{A}_{\mathrm{s}}$ & 56.56 & 2411 & $\mathrm{~mm}^{2}$ \\
\hline Area of compression reinforcement & $\mathrm{A}_{\mathrm{s}}$ & 56 & 1607.7 & $\mathrm{~mm}^{2}$ \\
\hline Shear reinforcement & St & 376.8 & 3021.9 & $\mathrm{~mm}^{2} / \mathrm{m}$ \\
\hline Yield strength of reinforcement steel & $f y$ & 335 & 552 & $\mathrm{MPa}$ \\
\hline Cylinder compressive strength of concrete & $f c$ & 23 & 80 & $\mathrm{MPa}$ \\
\hline Ultimate tensile strength of carbon strip & $\mathrm{Tf}$ & 490 & 3900 & $\mathrm{MPa}$ \\
\hline Modulus of elasticity for carbon & Ef & 73.1 & 250 & $\mathrm{GPa}$ \\
\hline Depth of tension reinforcement & $\mathrm{d}$ & 89 & 416 & $\mathrm{~mm}$ \\
\hline Concrete cover in tension area & cov & 11 & 51 & $\mathrm{~mm}$ \\
\hline
\end{tabular}

\subsection{Training of the Neural Networks}

Back propagation networks are known for their ability to generalize well on a wide variety of problems. They are used for a vast majority of working neural network applications. The standard type of back-propagation network in which every layer is connected or linked to the immediately previous layer. The number of input and output neurons was set equal to the number of inputs and outputs respectively.

From the 85 beams data collected from experimental work, obtained by the simulations, 75 of them was used in the training of the neural networks, 10 was used for tests with the obtained networks. Perceptron Multilayer (PML) networks, with back-propagation algorithm were used for the training. The multi-layer feed forward back-propagation technique is implemented to develop and train the neural network of current research where the sigmoid transform function adopted.

The Levenberg-Marquardt (LM) techniques built in MATLAB proved to be efficient training functions, and therefore, are used to construct the NN model [24]. This training function is one of the conjugate gradient algorithms that start training by searching in the steepest descent direction (negative of the gradient) on the first iteration.

The LM algorithm is known to be significantly faster than the more traditional gradient descent type algorithms for training neural networks. It is, in fact, mentioned as the fastest method for training moderately sized feed-forward neural network [25]. While each iteration of the LM algorithm tends to take longer than each iteration of the other gradient descent algorithms, the LM algorithm yields far better results using far less iteration, leading to a net saving in computer processor time over the other methods. One concern, however, is that it may over fit the data. The network should be trained to recognize general characteristics rather than variations specific to the data set used for training. 


\subsection{Network Data Preparation}

Preprocessing of data by scaling was carried out to improve the training of neural network To avoid the slow rate of learning near end points specifically of the output range due to the property of the sigmoid function which is asymptotic to values 0 and 1 , the input and output data were scaled between the interval 0.1 and 0.9. The linear scaling equation:

$y=\left(\frac{0.8}{\Delta}\right) X+\left(0.9-\frac{0.8 X_{\max }}{\Delta}\right)$

Was used in this study for a variable limited to minimum $\left(X_{\min }\right)$ and maximum

$\left(X_{\max }\right)$ Values given in Table 1 with:

$\Delta=X_{\max }-X_{\min }$

It should be noted that any new input data should be scaled before being presented to the network and the corresponding predicted values should be un-scaled before use

\subsection{The Model FS17-1}

At first time the model with seventeen inputs (FS17-1) was trained and tested using the experimental data. A four-layer feed forward neural network was developed. The properties of the models are shown in table 2.

Fig. (3) Shows actual and predicted ultimate load of regression for testing data, the correlation coefficient was found to be 0.97558 .

Because the weight of the back-propagation network cannot be easily understood in the form of a numeric matrix, they may be transformed into coding values in the form of a percentage by dividing the weights by the sum for all the input parameters, which gives the relative importance for each input parameter to output parameter.

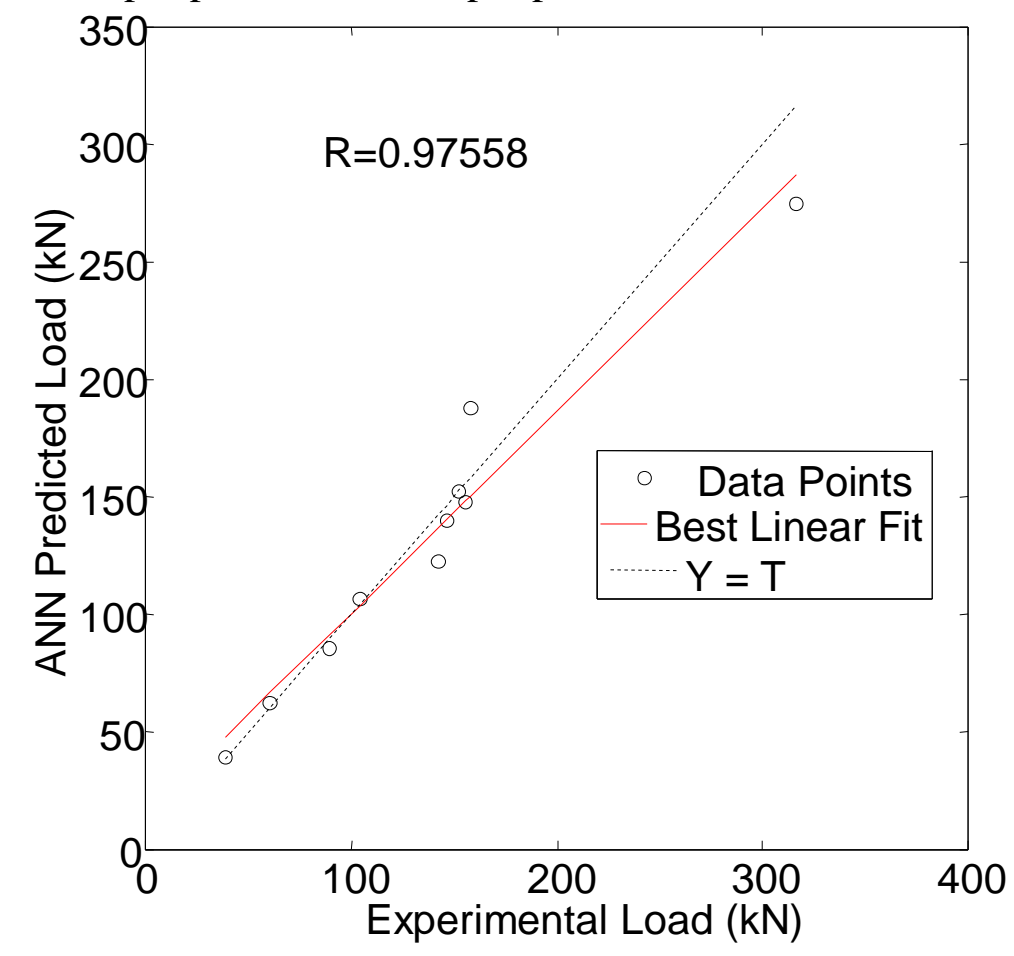

Fig. (3) Comparison of ultimate load prediction for ANN model FS17-1 
The relative importance for various input parameters are shown in Fig. 4. As the figure indicates, the major important parameter is the carbon thickness $(26.58 \%)$ while the most of other input parameters has insignificant importance on the predicting of ultimate load (10.24\%-2.43\%), hence the parameters with low importance can be omit from input parameters of network. Beside the carbon thickness, four parameters were select from the residual sixteen parameters, for developed new ANN model, these are (length of carbon (Lf), yield strength of steel (fy), concrete strength (fc) and concrete cover (cov)).

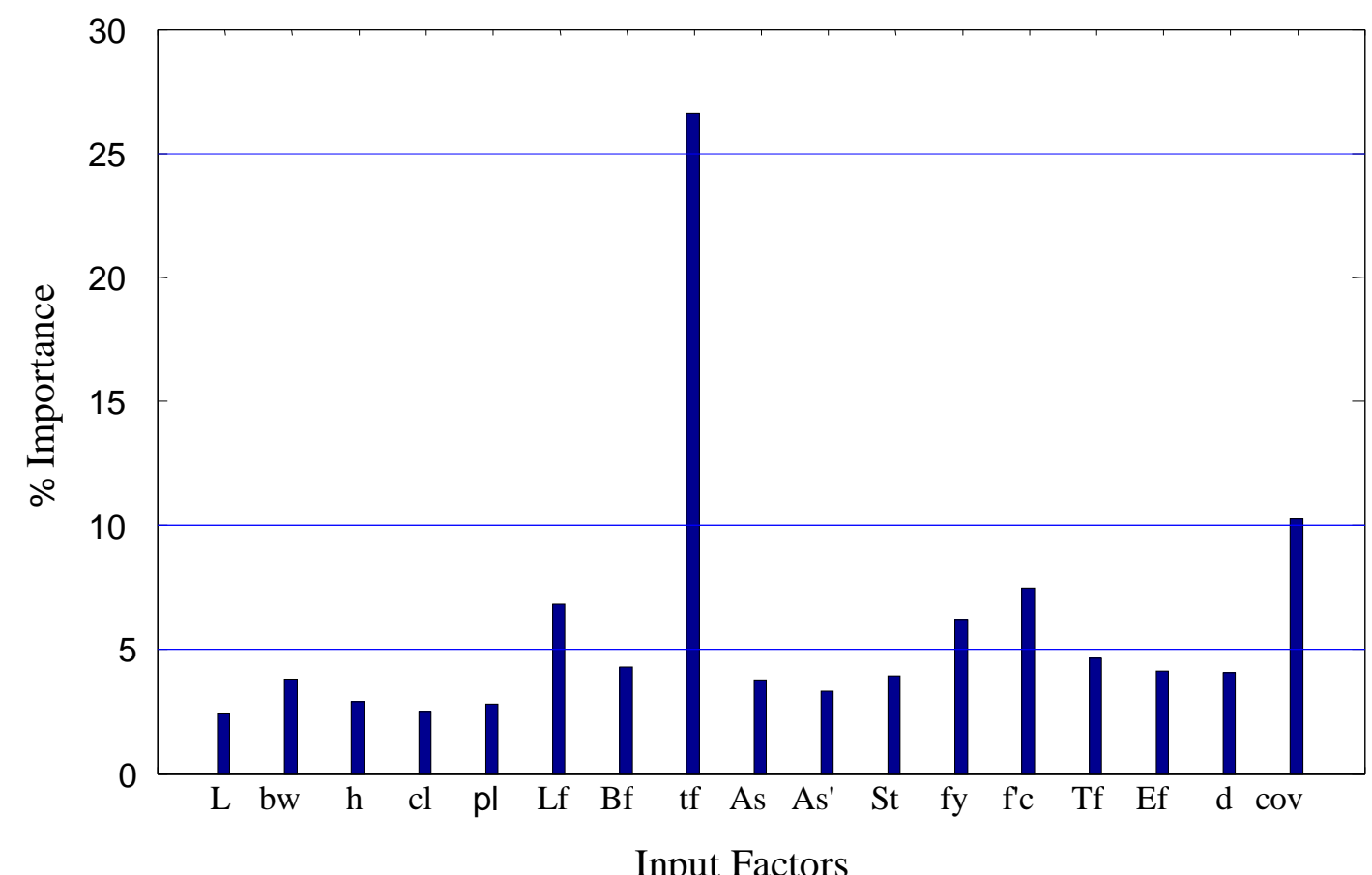

\section{The Mods}

Fig. (4) Relative importance of input parameter for ANN model FS17-1

The second ANN model was developed with five input parameters and ultimate load as output. From 85 data, 60 unique data were obtained and divided into 51 training and 9 testing data. The properties of the FS5-1 model are shown in table 2.

Table (2) Properties of models

\begin{tabular}{|l|l|l|}
\hline Model & FS17-1 & FS5-1 \\
\hline Architecture & $17-30-30-1$ & $5-18-18-1$ \\
\hline Activation functions & Logsig- logsig- logsig & Logsig- logsig- logsig \\
\hline Learning algorithm & LM & LM \\
\hline Performance function & 'mse' & 'mse' \\
\hline Performance & 0.0003 & 0.002 \\
\hline
\end{tabular}

Fig. (5) Shows a plot of actual tested parameters against corresponding ANN predictions. A linear correlation can be observed and the correlation coefficient was found to be ( 0.97923), thus it can be concluded that the ANN can successfully modeled the ultimate load of reinforced concrete beams strengthen by carbon FRP using only five input parameters instead of seventeen parameters.

To compare the neural network results with aforementioned ACI 440 R2 Code formulas, the same test data are used to calculate the predicted ultimate load capacity using the 
ACI 440-R2 formulas. It is shown in Fig (5) and Fig (6) that the correlation coefficient is 0.97923 for ANN against 0.3287 for ACI $440 \mathrm{R} 2$. It is obvious that the ANN values are very comparable with experimental results within the range of applicable data. And the ANN prediction is clearly better than the prediction of ACI $440 \mathrm{R} 2$.

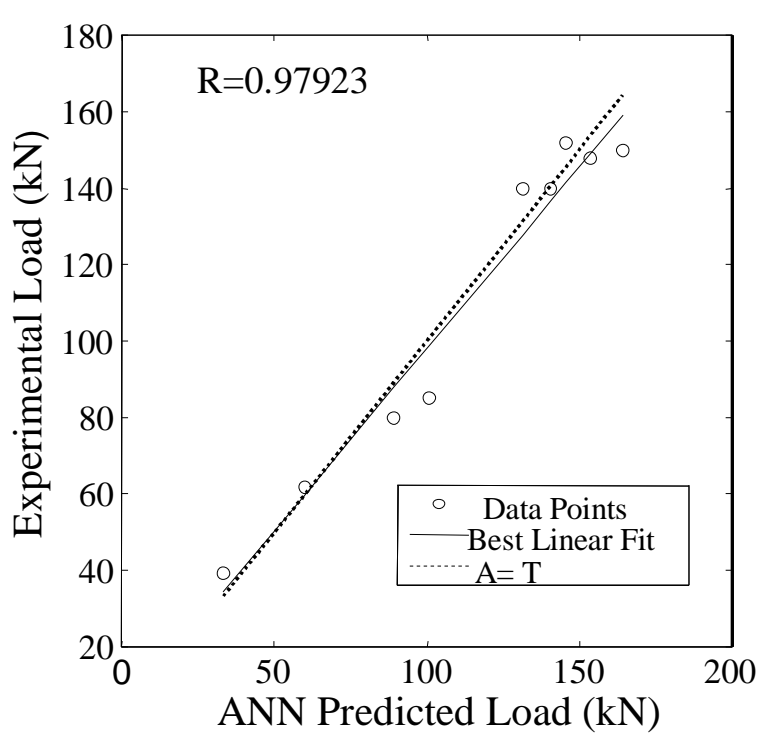

Fig. (5) Comparison experimental with ANN model FS5-1.

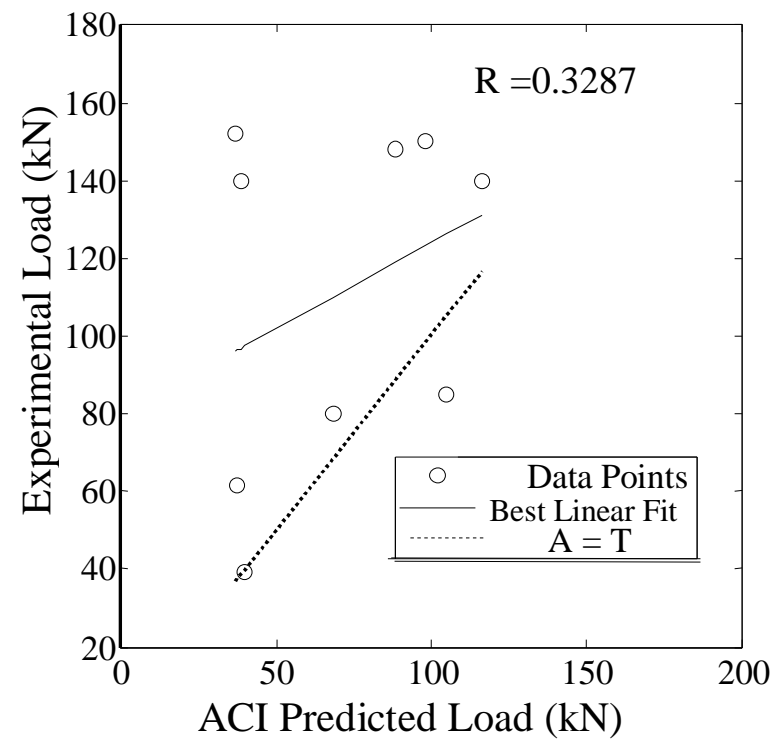

Fig. (6) Comparison experimental with ACI- 440- R2 formulas.

\section{Parametric Studies and Sensitivity Analysis}

One advantage of neural network models is that parametric studies can be easily done by simply varying one input parameter and all other input parameters are set to constant values. Through parametric studies, it can verify the performance of the Fs5-1 model in simulating the physical behavior of reinforced concrete beams strengthen by carbon FRP.

\subsection{Effect of Carbon Thickness}

Fig (7) shows the ANN prediction of variation of load capacity and carbon thickness for a rectangular beam with yield strength fy $=400 \mathrm{MPa}$, concrete strength $f c^{\prime}=40 \mathrm{MPa}$ and concrete cover cov $=40 \mathrm{~mm}$ and with different values of carbon length. As the figure shows, the ultimate load increases with increasing the carbon thickness. Fig (8) shows the ANN prediction of variation of load capacity and carbon thickness for a rectangular beam with yield strength $\mathrm{fy}=400 \mathrm{MPa}$, carbon length $\mathrm{Lf}=300 \mathrm{~mm}$ and concrete cover cov $=40 \mathrm{~mm}$ and with different values of concrete strength for the same beam. The figure again shows that the ultimate load increase with increasing the carbon thickness on the other hand the figure shows insignificant effect of concrete strength on the ultimate load of reinforced concrete beams strengthen by carbon FRP. This result is conform with that obtained by Bobin and et-al [22]. 


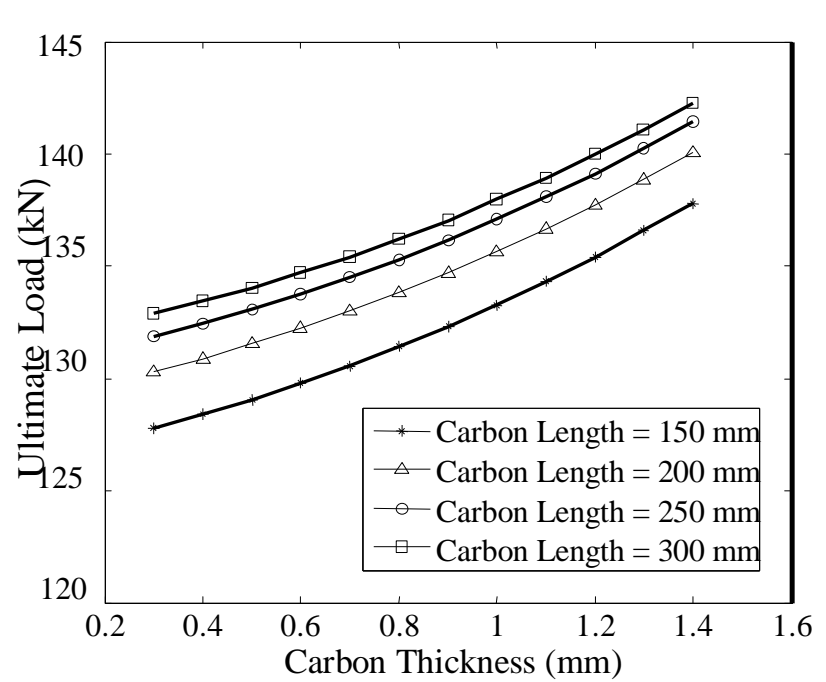

Fig. (7) Variation of the ultimate Load with carbon thickness and length as predicted by ANN

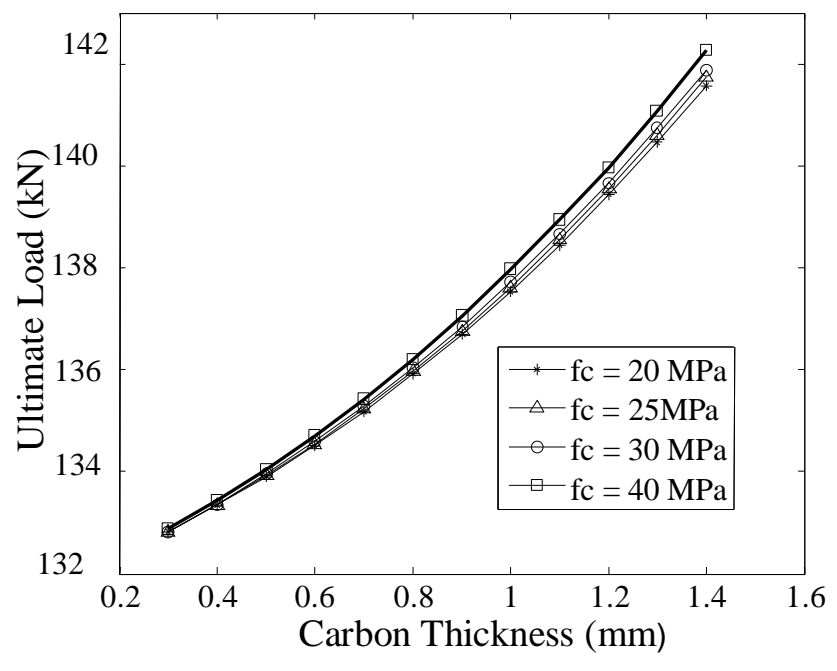

Fig. (8) Variation of the ultimate Load with carbon thickness and compressive strength as predicted by ANN

\subsection{Effect of Concrete Strength.}

Fig (8) and Fig (9) shows the ANN prediction of variation of load capacity and concrete strength $f c^{\prime}$ for a rectangular beam of different values of carbon thickness and length respectively. For the same carbon thickness or length there is no significant increase in the ultimate load capacity of the rectangular beam with increase of concrete strength.

\subsection{Effect of Carbon Length.}

Fig (9) shows the ANN prediction of variation of load capacity and carbon length Lf for a rectangular beam of different values of concrete strength. For the same concrete strength, the ultimate load increase with increasing the carbon length. Same result is observed from Figs (10). And it conform with the result obtained by Pham and Al Mahidi [21].

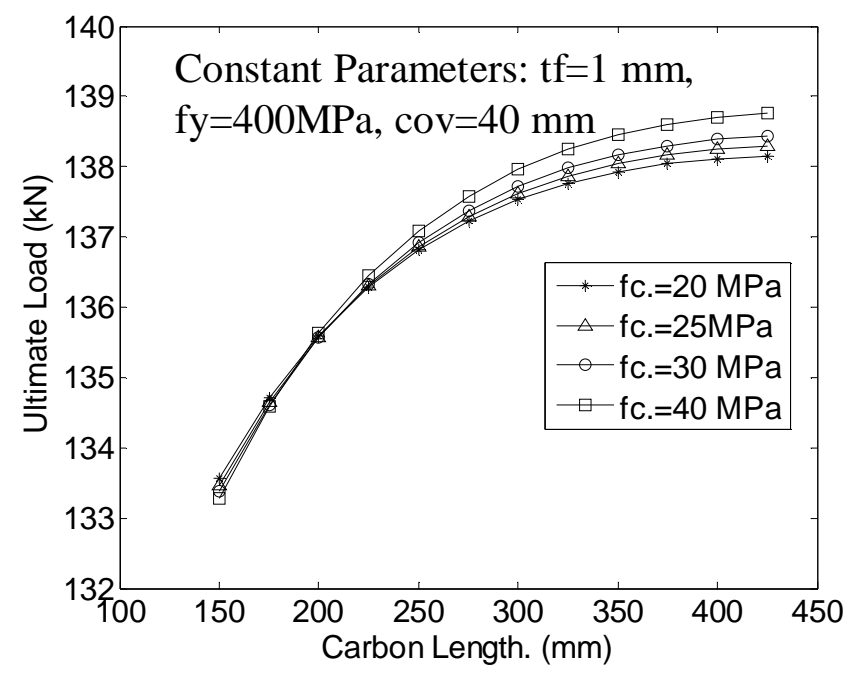

Fig. (9) Variation of the ultimate Load with carbon length and compressive strength as predicted by ANN

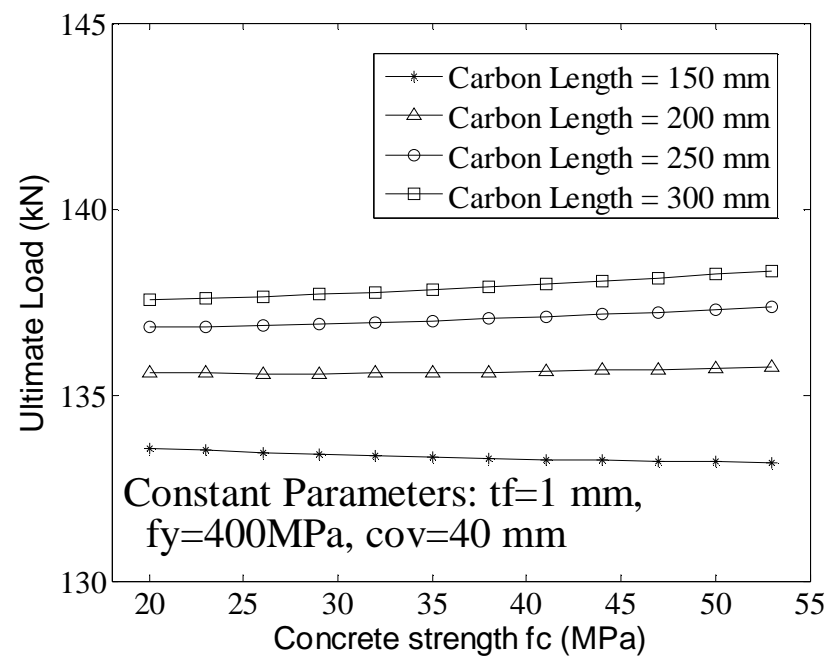

Fig. (10) Variation of the ultimate Load with compressive strength and carbon length as predicted by ANN 
Fig (11) shows the ANN prediction of variation of load capacity and concrete cover (cov) for a rectangular beam of different values of concrete strength. For the same concrete strength the ultimate load capacity of the rectangular beam increase with increasing of concrete cover. For concrete cover up to $38 \mathrm{~mm}$, the ultimate load capacity decrease with increasing concrete strength, the relationship is reverberate for concrete cover more than $38 \mathrm{~mm}$.

Fig (12) shows the ANN prediction of variation of load capacity and concrete cover (cov) for a rectangular beam of different values of carbon length. The ultimate loads are increase with increasing the concrete cover. The variations of the ultimate loads for $150(\mathrm{~mm})$ carbon length is (15.33) $\mathrm{kN}$ when the concrete cover is increase from $35(\mathrm{~mm})$ to $46(\mathrm{~mm})$, while the variation is (4.74) $\mathrm{kN}$ for $300(\mathrm{~mm})$ carbon length, on the other hand, it can be seen that the carbon length is effective when the concrete cover is small $(35 \mathrm{~mm})$, while it ineffective when the concrete cover is large (47 $\mathrm{mm})$

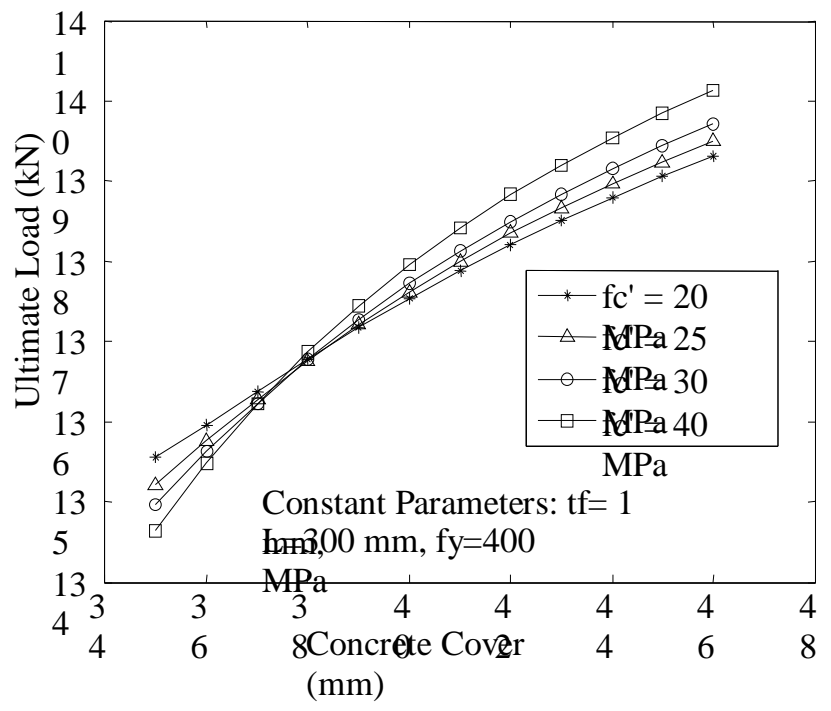

Fig. (11) Variation of the ultimate Load with concrete cover and compressive strength

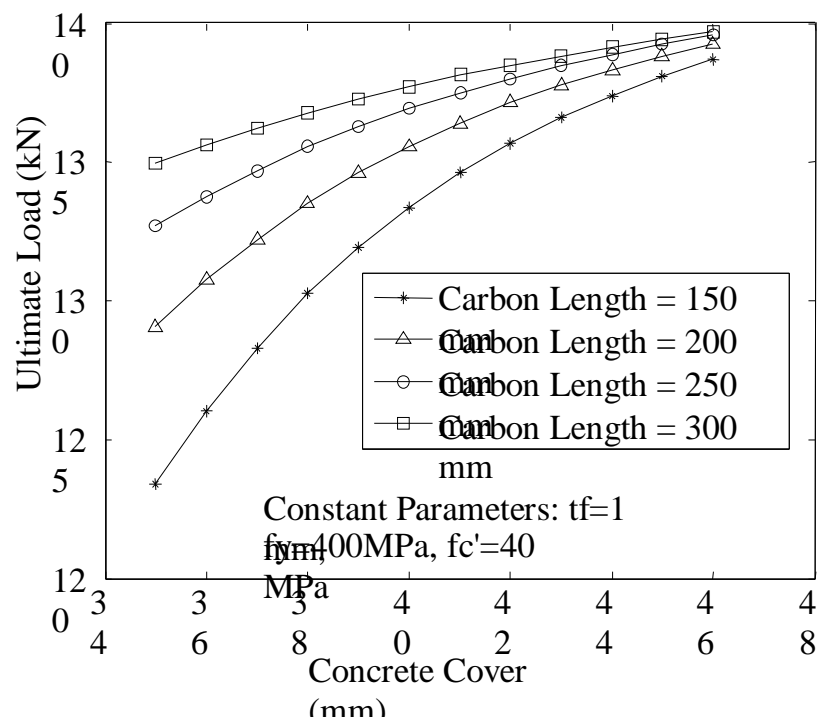

Fig. (12) Variation of the ultimate Load with concrete cover and carbon length as predicted by ANN

\section{Conclusion}

In this investigation, the feasibility of using a back propagation neural network to predict the ultimate load capacity of rectangular reinforced concrete beams strengthen with carbon FRB was carried out. The ANN prediction and experimental values are compared with the load prediction of ACI 440 R2 formulas. A sensitivity study of the parameters that affect load capacity of reinforced concrete beams was carried out. It can be concluded from this study that:

- Back propagation neural network (BPNN) with sigmoid function can be used successfully to predict the ultimate load capacity of rectangular reinforced concrete beams strengthen with carbon FRB accurately.

- ANN predictions of ultimate load capacity are more accurate than the ultimate load capacity prediction of ACI $440 \mathrm{R} 2$ formulas.

- ANN is an effective tool for running parametric study among several parameters that affect physical phenomenon in engineering as verified for the case of ultimate load capacity of reinforced concrete beams. 
- ANN is effective tools for execution importance studies of the input parameters that affect the predicting the out parameters, the input parameters with low importance can be omit to develop new ANN with significant importance parameters only.

- Carbon thickness is the major important parameters that affecting the prediction of the ultimate load capacity of rectangular reinforced concrete beams strengthen with carbon FRB.

- For the same carbon thickness or length there is no significant increase in the ultimate load capacity of the rectangular beam with increase of concrete strength.

- The ultimate load increase with increasing the carbon length.

- The ultimate load capacity of the rectangular beam increase with increasing of concrete cover.

\section{References}

1. Camille A. Issa, R. Awwad, and A. Sfeir " Numerical Modeling of Plain Concrete Beams Strengthened with Externally Bonded CFRP ", Computing in Civil Engineering, 2005, pp.

2. Wing Ho Cheung, "Neural Network Aided Aviation Fuel Consumption Modeling”, M. Sc. Thesis, Blacksburg, August 1997.

3. Hegazy, T., Tully, S. and Marzouk, H. "Neural Network approach for Predicting the Structural Behavior of Concrete Slabs", Canadian Journal of Civil Engineering, Vol. 25, No. 4, Aug (1998). pp. 668-677.

4. R. Haj-Ali, H. K. Kim, "Nonlinear Constitutive Models for FRP Composites Using Artificial Neural Networks", Science Direct, Mechanics of Materials, 39, 2007, pp.1035-1042.

5. Bimal Babu Adhikary, and Hiroshi Mutsuyoshi, "Prediction of shear strength of steel fiber RC beams using neural networks", Science Direct, Journal Construction and Building Materials 20 (2006), pp. 801-811.

6. ACI Committee 440F, "Guide for the Design and Construction of Externally Bounded FRP System for Strengthening Concrete Structures”, 2002.

7. P. Alagusundaramorthy, I.E. Harik, and C. Choo, "Flexural Behavior of R.C. Beams With Carbon Reinforced Polymer Sheets or Fabric", Journal of Composite for Construction,Vol.7, No.4, November, 2008, pp. 292-301.

8. J. Valivonis, T. Skuturna, " Cracking and Strength of Reinforced Concrete Structures in Flexure Strengthened with Carbon Laminates" Journal of Civil Engineering and Management, Vol. XIII, No 4, 2007, pp. 317-323. 
9. S. F. Bren a, and B.M. Macri, "Effect of Carbon-Fiber-Reinforced Polymer Laminate Configuration on the Behavior of Strengthened Reinforced Concrete Beams", Journal of Composites for Construction, Vol. 8, No.3, June 1, 2004. ASCE, 2004, pp.229-240.

10 N. Kishi, G. Zhang, and H. Mikami, "Numerical Cracking and Debonding Analysis of RC Beams Reinforced with FRP Sheet", Journal of Composites for Construction, Vol. 9, No. 6, December, 1, 2005. ASCE, pp. 507-514.

11. M. Arduini, and A. Nanni, "Behavior of Pre Cracked R.C. Beams Strengthened With Carbon FRP Sheets" , Journal of Composites for Construction, Vol. 1, No. 2, May, 1997. ASCE, pp. 63-70.

12. A. Chahrour and K. Soudki, "Flexural Response of Reinforced Concrete Beams Strengthened with End-Anchored Partially Bonded Carbon Fiber-Reinforced Polymer Strips", Journal of Composites for Construction, Vol. 9, No. 2, April 1, 2005.ASCE, pp. 170-177.

13. A.Saeed, Shah.A., and Nadar.A., "Strengthened and Rehabilitation of Concrete Structures With Carbon Fiber Reinforced Polymer CFRP”,

14. ZHANG A., J. Wei-liang, and, LI Gui-bing, "Behavior of Preloaded RC Beams Strengthened With CFRP laminates", Journal of Zhejiang, University Scince, A 2006, Vol., 7No. 3, University of Shangha, China, pp. 436-444.

15. N. D. Minah, Chan T. Khuan, and Cheong H. Kait, " Effect of Plate Length of Reinforced Concrete Beams Bounded With CFRP Plates", report RG 43/97, Nanyang Technological University Research, 1997, pp.1-6.

16. H. Toutanji, L. Zhao, and Y. Zang, " Flexural Behavior of Reinforced Concrete Beams Externally Strengthened With CFRP Sheet Bounded With an Inorgic Matrix", Science Direct, Engineering Structures, 28, 2006, pp.557-566.

17. M.R. Esfahani, M.R. Kianosh, and A. R. Tajari, " Flexural Behavior of Reinforced Concrete Beams Strengthened by CFRP Sheet”, Science Direct, Engineering Structures, 29, 2007, pp.2428-2444.

18. P. Fanning and O. Kelly " Smeared Crack Models of RC Beams With Externally Bounded CFRP Plates" Computational Mechanics , 26, 2000, pp.325-332.

19. Y. Dong, M. Zhao, and F. Ansari, " Failure Characteristics of Reinforced Concrete Beams Repaired With CFRP Composites", Proceeding of the third international conference on composites in infrastructure. San Francisco, California: ICCI; 2002, pp. 126-40.

20. A. Carolin, B. Talisten, and A. Hejll, “ Concrete Beams Exposed to Live Loading During CFRP Strengthening” Journal of composites for construction. 2005 ; vol. 9, nr. 2, March/April, pp. 178-186 
21. H. Pham, R. Al-Mahaidi, “ Experimental Investigation into Flexural Retrofitting Reinforced Concrete Bridge Beams Using FRP Composites", Science Direct , Composite Structures, 66, 2004, pp.617-625.

22. F. B. Bodin, E. David, and E. Ragneau, "Finite Element Modeling of Flexural Behavior of Externally Bounded CFRP Reinforced Concrete Structures" Science Direct, Engineering Structures, 24, 2002, pp.1423-1429.

23. M. Maalej, and K.S. Leong, " Effect of Beam Size and FRP Thickness on Interfacial Shear Stress Concentration and Failure Mode of FRP Strengthened Beams", Science Direct, Composites Science Technology, 65, 2005, pp.1148-1158.

24. D. Howard and B. Mark, "Neural network toolbox for use with MATLAB", User's Guide, Version 4. The Math works, Inc 2002.

25. Simon Haykin, "Neural networks a comprehensive foundation", 2nd ed., Prentice Hall, New Jersey, 1999 